\title{
Social mechanisms of performance systems
}

\section{Halvor Holtskog Geir Ringen}

\begin{abstract}
Production systems have continuously evolved since early attempts to standardise parts, processes and work modes to enhance mass production. This was further refined by the Japanese automotive industry, which has been the global benchmark for decades. Lately, such systems have been developed as company specific production systems to create common identities and production principles, to form global production networks and performance systems. The purpose of this article is to investigate the introduction of new systems, or the introduction of new combined systems, casting light on what happens inside the organisation, making these systems work over time. The article illustrates how true change occurred in a multinational company over the period from 2000 to the present. The key point for this study is not the system as a formalised structure for improving overall company efficiency, based on measures regards to flexibility, cost, quality and time. Our concerns relate to mechanisms and agents behind the system itself, and evolution over time. We focus on the two mechanisms, mentor-sponsor and insider-outsiders, understanding how these mechanisms are related and eventually support each other. The article argues that popular managerial and performance tools and systems are less important than how mechanisms for initiating and maintaining focus on performance are managed as a symbiosis between local and central change agents.
\end{abstract}

Keywords: Production system, mentor-sponsor, insider-outsider, change agents 


\section{Introduction}

Manufacturing industry has long focused on different manufacturing systems. Some of the most popular systems are Total Quality Management (TQM), and Lean (Bhasin \& Burcher 2006; Bralla 1999; Hasenkamp 2009; Ishikawa 1985; Liker \& Morgan 2006; Oakland 2003). It is generally understood that these systems have built-in critical tools, which if followed, will bring the organisation to success or gaining competitiveness. This success or competitiveness is delivered by special focus on specific areas of doing business. Total Quality Management, for instance, focuses on how to make quality thinking integrated into every value adding and non-value adding process. Many of these systems are highly celebrated, and documented by many different case studies. This puts the value of the systems as the main explanation for the success uncovered in case companies.

This article takes a closer look at this general understanding. Companies introduce various systems over time, and invest huge resources. Therefore, it is vital to understand the mechanisms for introducing and upgrading performance systems.

The purpose of this article is to investigate the introduction of new systems or new combined systems. We shed light on what happens inside the organisation, making these system work. The researchers have followed one big multinational corporation over 18 years, with close collaboration with the people responsible for working with these systems throughout the years. Mechanisms for maintaining and introduction of systems are at the centre of interest. The research follows a multi-dimensional research methodology, where different information and data gathered throughout the years are compared and analysed.

\section{Theory}

Changes of performance systems, like TQM, Lean, etc, are not innovation or initiation, according to March and Simon (March et al. 1994, p. 195). They argue that it is framed inside a well-defined performance programme. Rather, it is an evolution of work place behaviour and work place practice. Complexity is another key component for the success of performance programs (Holberg 2006). Lack of attention to complexity in change or performance programmes harms the company "... the situation gradually deteriorated, to end with everyone heroically sitting and doing 'more of the same' in order to save the situation" (Holberg 2006, p. 134). Whitley (Whitley 2007) looked at complexity in the form of the project-based firm. Skilled workers co-ordinated their work directly, without reliance on management and organisational procedures (Whitley 2007, p. 247).

Development of such skilled workers depended on the longevity and co-ordination procedures in the firms involved. Kurt Lewin developed a theory of change, unfreezing, moving, refreezing, as a simple chain (Lewin 1951). This tried to guide organisational change without directing too much attention to complexity; building on the concept of rational management, with planned change in the centre. Several researchers have later disagreed with the concept of rational management, and especially planned change. Christensen (Christensen 1997) summarised it by analysing why brilliant companies sometimes failed. He claimed that failure came because of good management in a complex environment. March (March 1988) regarded narrow rationality with order and control as counterproductive when the goal is innovation, change, and creativity.

This article focuses on long-term organisational changes which accompany the evolution of performance systems. French et al. define organisational development (OD) as "intervention techniques, theories, principles, and values that show how to take charge of planned change efforts and achieve success" (French \& Bell 1995). OD has had some interest from the research community, in the sense of how researchers should or could interact with companies and organisations (Levin 2004). However, this article looks at organisational change or development 
where the organisational members themselves do the work, asking about the mechanisms involved in making OD happen.

This is also the focal point of Klein's research (Klein 2004), dealing with complexity and the concept of rational management and planned changed. She coins true change as "when ideas or concepts become embedded in the underlying assumptions about how work is done. True change means the new ideas become institutionalised, and are no longer dependent on a change agent or champion to support them" (Klein 2004, p. 1). True change should be understood as change introduced when current knowledge and experience in the organisation cannot solve the challenges. It is similar to push and pull inventory in Lean thinking. You do not produce a product if it is already in the inventory. The signal for starting production is when the product leaves the inventory. The same logic applies for change or true change, only changing when the current system, knowledge, expertise etc. cannot solve the problem.

Another central point is the notion of insider-outsider view. An organisation needs people inside who can think, and relate to it as an outsider would. These people are able to see concepts, and have ideas originated from outside that can benefit the organisation. Bringing in fresh ideas and concepts develops the organisation over time. These pull changes occur through personal networks, using personal contacts before a search through knowledge management systems in the company for that particular expertise. The personal network will grow and increase its importance over time. Klein identified two central roles in network and insider-outsider view, sponsors and mentors (Klein 2004, pp. 155-162). Sponsors are the leaders who find the proper job assignment for the insideroutsiders. Mentors are explained as the network navigators, helping people to find the right contact or expertise. Having sponsors and mentors is not all positive. For instance, it can limit diversity by not thinking like an outsider, monitoring pace, and lack of chemistry or losing organisational influence. Overall, the true change perspective on organisational change is a balancing act between competing forces, like insider / outsider, organisational assumptions / new insights, requirement of an open mind / working from within the organisation. These dilemmas will be discussed further in the article.

\section{Production system}

Lean

Over the last couple of decades, lean production has become the global blueprint for large scale, repetitive manufacturing. Lean production was popularised by the IMVP study (Krafcik 1988; Womack, Jones, \& Roos 1990), which argued that the competitive advantage of Japanese automobile manufactures could be attributed to their superior way of organising supplier relations, product development and operations. Lean production was presented as a systematisation and re-labelling of the Toyota Production System (TPS) in the 1930s and continuously refined thereafter (Holweg 2007; Spear \& Bowe, 1999). Shah and Ward (2007, p. 791) defines lean production as "an integrated socio-technical system whose main objective is to eliminate waste by concurrently reducing or minimising supplier, customer, and internal variability". "Waste" refers to excess inventory, excess capacity and activities that incur costs without adding customer value (Ohno 1988). When variability is reduced, production volume, delivery times and quality become more predictable, and production can be levelled out to balance workload and capacity utilisation. Variability reduction is achieved through a set of practices such as standard operating procedures, just in time, total quality management total productive maintenance and human resource management (de Treville \& Antonakis 2006; MacDuffie 1995; Shah \& Ward 2003). According to popular literature, lean management is about long-term philosophy and developing individuals and the organisation through continuous improvement (Liker 2004; Spear \& Bowen 1999). However, it remains to be 
explored how these principles are institutionalised in managerial roles, organisational agents, responsibilities and competencies.

\section{System development}

Some researchers have tried to define production systems in general terms. Hubka and Eder (Hubka \& Eder 1988) attempted to do so by presenting four subsystems; 1) the human system, 2) the technical system, 3) the information system, and 4) the management system, which all affect the transformation process from raw materials to products. A more recent description is provided by Clarke, who claims that production systems represent the changing nature of the form and function of standardisation (Clarke 2005). By standardisation, he does not exclusively mean product standardisation but also standardisation of processes and work. Nevertheless, the history of production systems goes far back in time, and the military is often said to be a forerunner (Cowen 2000).

During the 18th century, machines, jigs, fixtures and gauging systems developed towards part conformity and standardised interchangeable parts. Application of standardisation and production systems went from military arms production to sewing, meat packing and to the early automotive industry (Hounshell 1984). Instead of individual freedom of the artisan to design and produce, production engineers now made detailed drawings and guidelines, hence eroding the need for operators to think about work processes. The next step was to fragment and standardise work tasks according to time and motion studies (Taylor 1911), leading to increased efficiency alongside improved product quality. Complexity was handled by subdividing the problem into minor tasks, easy to perform, which require a minimum of training and learning at the shop floor level. This approach separated thinking, doing, improving and performing, and assumed that workers were primarily driven by monetary incentives (Hackman \& Oldham 1976). Mass production represented the first holistic production system, taking into account technology, processes, work standards, as well as social standards regulating payment and working conditions.

The next major step in the evolution of production systems is the Toyota Production System (TPS). The Toyota Motor Company was established in 1930, and this new company struggled through the 1930s by making poor quality vehicles based on primitive technology (Liker \& Hoseus 2008). They decided to benchmark their processes against Ford and GM, but the implementation effort was put on hold because of World War II. The work continued in the 1950s (Liker \& Meier 2006), where Toyota found that the mass production system was wasteful batch-production, building up huge work-in-process inventory throughout the value chain: pushing products to the next process step (Womack, Jones, \& Roos 1990). This rigid and capital-intensive system was seen as inappropriate for serving the dispersed, low volume market in Japan. In addition, the use of highly specialised workers at the American auto-companies, which were easy to replace, was an approach irreconcilable with Japanese work culture. This view emphasises the human beings as the bedrock of all organisations in which solutions to problems are highly situation dependent. An example by Peter Drucker, referred to by Kamata (Kamata 2002), shows that there was a long way to go for the theory of collaboration. In the late 1940s, General Motors introduced what was later called "quality circles" as a partnership between managers and workers to improve products and processes, but the United Auto Workers (UAW) resisted, and argued that even asking workers about their jobs was an unfair labour practice. The TPS therefore proposes a different system of standards, to achieve manufacturing efficiency with a minimum of resources through continuous improvement. The latter is regarded as the major responsibility of the shop floor worker. In the beginning of the 1950s American 
management practices, such as quality control, pioneered by Deming (El-Haik \& Al-Aomar 2006), were introduced and implemented.

During the early 1960s Toyota (Clarke 2005) introduced the first company-wide total quality system, based on "Quality at the source" and learning by doing principles. Quality is today one of the main principles of the TPS, focusing on in-process quality and stabilisation of processes. The success of Toyota was soon recognised by other Japanese companies, and the spread of TPS to suppliers pushed towards formalisation of the system (Monden 1983): resulting in the first publication by Ohno in 1978. This development- and formalisation process continued throughout the 1980s and 1990s, as Toyota expanded its operations globally. Finally, the MIT study concluded that the performance of TPS was not impacted by culture, history, and social background, stating the new universal lean paradigm (Nomura \& Jürgens 1995). From a learning perspective, TPS can be viewed as routinised learning capabilities applied to real life problem solving (Spear \& Bowen 1999).

Another production system, known as the Volvo Uddevalla experiment, is based on principles of industrial democracy and teamwork. This system encourages workers to help each other to solve complex problems and smoothing out the workflow in parallel lines (Clarke 2005). Placing human considerations at the centre, Volvo was aiming at increased flexibility, worker motivation and of course sustained efficiency and quality. The system demonstrated some promising features, but the factory closed down in a few years due to large variations in work methods and product quality. Today most manufacturing companies build and develop their production system based on the TPS. It is claimed that Lean is not an option: it is mandatory for manufacturing firms operating in global markets (Liker \& Hoseus 2008). Hence, a competitive factor is how companies manage to evolve from a company specific production system to a company-wide production system (Netland \& Sanchez 2014).

The latter raises many questions about degrees of freedom, and involvement in implementing such systems at different locations. To build a shared and unified mind-set that allows for superior technological exploitation in a modern and networked organisation is not an easy task. Through the last decade there has been a strong trend among multinational companies to implement company-specific Lean production systems (Netland \& Aspelund 2012). Companies like Volvo, Siemens, Hydro and Volkswagen try to co-ordinate continuous improvements across subsidiaries and national borders. The benefits of a centrally co-ordinated approach are cost control, sharing of best practices within the network, developing a common improvement culture, and increased transparency between network companies (Goel \& Chen 2008). Coincident with the trend, there are numerous pitfalls: improvement programmes in general have shown no, or at the best temporary, effects (Anand, Ward, Tatikonda, \& Schilling 2009), the autonomy of the local plant is potentially harmed (Maritan, Brush, \& Karnani 2004), and a centralisation of the company culture can reduce the ability to innovate (Henderson, Alamo, Becker, Lawton, \& al. 1998). All too often, it is the tools that are focused, and often it is the only focus.

State-of-the-art research clearly points out that there is a lack of generic and normative models guiding these processes, and how they should be performed successfully (Barnes 2008; Chakravorty 2009; Goel \& Chen 2008; IfM 2007; Trikman 2010). Research has shown that improvement projects such as Lean are often elusive and not sustained (Abrahamson \& Eisenman 2008; Bateman 2005). An overall question regarding corporate improvement programmes is how tightly or loosely the programme should be managed. On one hand it is evident that optimisation of the network demands vigorous control, but on the other hand it is equally evident that simplification through distribution of responsibility and authority is probably the only practical strategy in global complex enterprises. Trikman (2010) stresses that business process management is indeed a complex task, spanning organisational design, management, information systems and social challenges. In the future, companies 
will take a greater and more proactive control over their production networks (Ferdows 2008). There is a call for more nuanced research, with a focal on the various meeting points between local and global actors. A sought-after strategy is to develop and maintain a global company culture that is built upon values which consolidate the "glocal" competitive advantage (Robertson 1995). By this is meant local solutions that also are sustainable at the global level.

\section{Methodology}

\section{Multiple Triangulation as a Multidimensional Analysis}

Flick pointed out that qualitative research often had multi-methods in focus (Denzin \& Lincoln 1994; Flick 1998, p. 229). The metaphor of triangulation comes from military usage and naval navigation where multiple reference points were used to pinpoint, through geometry, the exact position of an object (Smith \& Kleine 1986). "The combination of multiple methodological practices, empirical materials, perspectives, and observers in a single study is best understood, then, as a strategy that adds rigor, breadth, complexity, richness, and depth to any inquiry" (Flick 1998, p. 231). One common misconception is that triangulation is used in social science to check and validate studies. Achieving consistency across data sources or methods can be useful; however, Patton (Patton 2002) argued that inconsistencies reveal an opportunity to uncover deeper meaning in the data. The same argument can be found in Miles and Huberman's book, Qualitative Data Analysis (Miles \& Huberman 1994, pp. 266 - 267). Yeasmin and Rahman (2012) offer another support for the argument of uncovering deeper meaning in the data. They also point out that triangulation tends to support interdisciplinary research, where theories from different disciplines helps to deepen and widen our understanding, also arguing for triangulation as something that is natural to humans and is a common way of thinking. Alternatively, "There may be a correspondence between life as lived, life as experienced, and life as told, but the anthropologist should never assume the correspondence, or fail to make the distinction" (Bruner \& Plattner 1984, p. 7). Not only should anthropologists never assume or fail to make such distinctions, all social scientists should keep this in mind.

Going back to triangulation, (Denzin (1978) identified different types of triangulation, data source, investigator, methodological and theory triangulation. The two latter types are of interest to this article.

The methodological type uses different methods to study phenomena. Here there are two different forms, withinmethod and across-method. The first, within-method, relates to when a researcher uses one method, and uses different strategies within that method to analyse the data. The latter, across-method, is when the researcher uses and combines different methods to measure the same data. The rationale is that the flaws in one method can be the strength in another. A type of triangulation relates to the usage of different perspectives to interpret a single set of data.

There are three strategies for conducting theory triangulation. One strategy in theory triangulation is to move away from areas characterised by high degrees of theoretical incoherence. Another strategy is to select from contradictory propositions in the field, and to try to make sense for the researcher in relation to his or her background, or what he or she knows about the problem in advance. The third strategy is to develop one's own proposition and theory, called middle-range theory or grounded, substantive sociological theories (Denzin 1978, p. 304). The advantages for theory triangulation are minimising suppression of contradictory propositions (Westie 1965, p. 154); it permits the "widest possible theoretical use of any set of observations" (Denzin 1978, p. 306), and it encourages systematic continuity in theory and research. 
Some authors have pointed to another type, environmental triangulation, where usage of different locations, settings and other key factors relates to the environment where the investigation took place (Guion, Diehl, \& McDonald 2011). Miles and Huberman argued for yet another type, data type (Miles \& Huberman 1994, p. 267), which is about the usage of qualitative text, recordings and quantitative data. However, environmental triangulation and data type triangulation are not focused here. The automotive industry is truly a globalised industry, but it does not mean that local environments can have important key factors. Key factors in researching this article are not gathered specifically concerning environment, but some issues will be discussed. Data type triangulation is offered very little space in Miles and Huberman's book. It is difficult to separate this from data source and method triangulation.

It is argued that a combination of the basic triangulation types is ideal (Denzin 1970; Denzin 2009). A combination of triangulation, here called multi-dimensional analysis, will combine different types. Data sources will be triangulated in all three types, space, time, and person. When person data sources are used, the collective and interactive levels are focused.

\section{Validity}

Guba and Lincoln frame validity as a matter of both credibility and authenticity (Guba \& Lincoln 1989). As defined by Guba and Lincoln, credibility is "the idea ... of isomorphism between constructed realities of respondents and the reconstructions attributed to them" (Guba \& Lincoln 1989, pp. 236 - 237). The verification of such an isomorphism can be conducted through several techniques (Guba \& Lincoln 1989, pp. 237 - 250), and we look at each one, in light of four research projects:

Prolonged engagement: This is a substantial involvement in the field or in the case. The researchers have followed the company for 15 years, starting as $\mathrm{PhD}$ students with the case company as one of two primary cases.

Persistent observation: This adds depth to the scope, which prolonged engagement affords. The research has been with access to company documents, presentations, interviews and workshops.

Peer debriefing: The purpose here is to test the findings with someone directly involved in the situation, and to help bring propositionally tacit and implicit information of the evaluator. The two researchers have collaborated closely in each of the projects.

Negative case analysis: This is the analogue to a statistical test for quantitative data. It has not been in focus, but during our investigation of the company, it witnessed the financial crisis with turbulent times (Holtskog, Kaloudis, Carayannis, \& Ringen 2018, pp. 23-36).

Progressive subjectivity: This is the process of monitoring the evaluator's own developing constructions, and the degree of privileges to make one's own a priori assumptions dominate. This is a danger when following a company closely over time. Hopefully, having other researchers and companies' participation in the different projects, corrects this tendency.

Member checks: This deals with the testing of hypotheses, data, preliminary categories and interpretation with the members of the community from which the constructions are collected. Formal interviews were transcribed and sent to the respondent for approval, while only some informal interviews were transcribed; most were just written as notes in personal research journals. Still, the meaning and assumptions drawn from these notes were crosschecked with other members in the companies, as no meaning or assumptions are included without being 
crosschecked. This crosschecking was also applied to project meetings, focus group meetings and hallway talk, and some were checked with other written materials and recorded data in the management or quality systems. The research team has taken great precautions to avoid factual and interpretive errors.

Transferability (external validity: The company is multinational, with production sites in nearly every part of the world.

Dependability: This is about the stability of the data over time. The company has been very open and collaborated with the researchers well over the years. They have been open about setbacks and failures as well as successes.

Confirmability: This ensures that the data, interpretations and outcomes of inquiries are rooted in the proper contexts, which was already mentioned in the peer debriefing. Writing this article, the documentation gathered through the years were re-read and investigated.

\section{Data Usage}

Investigations were first characterised by getting to know the various systems, standards and formal documentation at the case company. Many formal documents were read, and a pattern gradually emerged. Confronting the managers with conflicting data, they opened up the rest of the organisation for interviews and surveys. Most of the formal documents, notes, in-depth interviews and forms were gradually built in a database in NVivo ${ }^{1}$. It served as a repository for coded data used for analysis and reflections. In total, the research spans over four major research projects funded by the Norwegian Research Council. With nearly 100 in-depth interviews, 30 workshops, three surveys, $2 \mathrm{PhD}$ theses and 10 master theses.

\section{Discussions}

The case company is a European actor within the metal production segment. This article reports upon a longitudinal study, following this case company and their production system trajectory and development for nearly 18 years. Throughout these years, the company has applied different strategies within the metal value chain. Going back to the year 2000, the case had an integrated value chain from metal production to development, production and supply of advanced safety components for the automotive industry. Attempts to structure production, improving quality and efficiency, by involving people in a more holistic view was introduced in the downstream subsidiaries. This initial phase is hereafter referred to as Stage one. The next strategic direction, Stage two, for the company was to move their operational footprint upstream, focusing on mining, refining and metal production. This new strategic position implied downscaling and sale of component manufacturing plants, including the subsidiary described above. Stage three is described as the era of transitioning from a production system to a business system perspective. The latter clearly integrates functions as quality, HR and process- and product development, stepping from lean viewpoint of the production system to a realisation and formalisation of a broader understanding of manufacturing in the global production network. Recently, the business system also incorporates technology, adding central principles of Industry 4.0, and how these interact with humans, to their system. Despite the strategic focus, value chain position, economical up- or downturns, growth in global production footprint, and added perspectives and functions to the production system: key resources for developing and executing the system remain the same. Further, we will describe each stage, from one to three, more in detail,

\footnotetext{
${ }^{1}$ A much used programme for conducting social research; http://www.qsrinternational.com/products nvivo.aspx
} 
to grasp the driving forces behind the evolution and the role, function and behaviour of the change agents, or making true change.

\section{Stage one}

The case company, like all actors competing in global value chains, has continuously improved their products and processes to be attractive to demanding customers. Prior to Stage one, there are traces of structured plant vice improvement efforts, starting in the early 1980s as a customer, or OEM (Original Equipment Manufacturer), driven initiative. Such pre-Lean efforts included tools and methods as JIT (just in time), TQM (Total Quality Management), and PDCA (Plan-Do-Act-Check), summarising to a set of sub-systems for overall improvement of enterprises and suppliers.

In brief, this approach can be said to involve the customer from a logistics point of view, securing the right product, with the right quality and right amount to the right destination in time. Supporting the stringent terms of delivery means that all technical equipment must be available, leading to a maintenance strategy through the TQM method. Least, humans need to be involved in order to generate and execute a stream of continuous improvement, structured and followed up by the PDCA. KPI-measures were developed and cascaded top-down to teams and individuals, focusing on quality, logistics and economy.

Depending on trends in these KPIs, the case company was rated up or down compared to other suppliers of the OEM. If we look at this period, the change agents were primarily external. The customer that initiated the improvement programme had the resources to assess production capabilities, make roadmaps and strategic alignments, transfer knowledge to key resources, and to review and follow-up based on KPIs. A mandatory programme was introduced by the core customer, with the aim to improve overall efficiency, cost and delivery accuracy.

During late 1980s and the 1990s the case company experienced a considerably growth in customer- and product portfolio, going from supplying a few core customers to many OEMs. Expanding the business was rooted in the need for light weighting, platform thinking and globalisation in the automotive industry. The former led to added customer base, the latter to interchangeable components across car models and platforms, and globalisation to the need for production capacity close to the customer in Europe, Asia and North America.

To step up with this strategy the company invested 200 MEUR in the late 1990s to increase capacity in new and existing plants. However, ambitious growth in combination new equipment start-up problems and component quality issues turned into an economical down, around the millennium. New manufacturing management was put in place to recover the case company, launching a holistic production system as part of the turnaround process. The new manager appointed an internal person as responsible for development of the production system concept, based on lean theories, best practices from industrial peers and local knowledge, and to implement and sustain the system in the organisation.

The production system programme was an adjustment of what is known as Toyota Production Systems, often referred to as a Japanese production philosophy. The content of the system is a vision of how production should be undertaken in the future, with a staircase as a symbol of the roadmap ahead, showing how the company could get to the vision. Important states for each step were assigned, where the first step is about understanding the current situation and the need for change, the next one is team organising and co-ordinating of tasks, the third related to process stability and plant capacity, approaching the steady state of continuous flow on one-piece 
production. At every step in the ladder, both the workers and the management have clear and simple tools and techniques to use to improve efficiency, reduce waste and thus increase earnings. The tools include unambiguous key performance indicators (KPIs) and whiteboards per team of operators with easy-to-read numbers and graphs. Every shift reports on issues such as production volume, quality issues, the maintenance tasks they have performed, possible irregularities in machines and uptime.

Team leaders and TPV co-ordinators were appointed and trained as internal ambassadors for the new system, responsible for applying principles, training their co-workers and making individuals and teams more knowledgeable and autonomous. One of the goals is to create greater independence for the workers, stating that the workers' acceptance and feeling of ownership are key in achieving the durable effects of changes.

Consequently, the system includes team organisation across hierarchical levels in the company. Thus, the production system is not only a set of tools and techniques, but also reflects a shift in the philosophy underpinning the production of automotive components. Throughout the first year this structured and more holistic production approach gained acknowledgement from support functions, where managers from HR and Economy become instrumental in implementing the system, contributing respectively from the educational side and the follow-up of KPIs and economic benefits. From this stage, five key resources, or change agents, are identified, top manager, overall system responsible, HR, Quality and Economy directors: all of them are to be found in central positions in the further stages.

\section{Stage two}

When the case company turned its focus upstream, and by 2009, in the midst of the global financial crisis, completely ended their downstream operations of making components, a production system approach was launched in the metals division during 2006. Declining aluminium metal prices and a relatively risky position on the global cost curve for smelters, this production system was initiated to make the organisation more robust and competitive. Previous improvement programmes had been directed towards maintaining the capital-intensive equipment through TPM programmes (Total Productive Maintenance). When taking the decision to develop, implement and follow-up the system, at least in the initial phases, it was considered to what degree the company had the internal capabilities to lead the work ahead. The alternative was to hire consultants and their base of experience from similar implementations. A long-term philosophy for the improvement work was chosen, and thus, internal key resources were searched for. A natural choice was the experienced team from the downstream subsidiary, hiring them one by one from 2006 to 2008 when scaling up the implementation phase.

Having a centralised team in place, the system had to be adapted to the current situation, context and business segment. It turned out that those competitors in the metals production business had been part of the IMVP ${ }^{2}$ programme, experiencing the concepts of Lean in a different context than mass production of components. Combining the knowledge the centralised team had from automotive production, with best practices from the business they were facing, made the foundation for the production system.

The Metal Production System became part of the case company's long-term strategy of being world class within safety, quality, productivity and profitability, and the system rests on the five underlying principles: standardisation of work processes, defined customer- and supplier relationships, optimised flow, dedicated teams

2 IMVP - International Motor Vehicle Programme was initiated in 1979 by MIT. The research project was renamed in 2013 to Programme on Vehicle and Mobility Innovation (PVMI) after running continuously through three phases. The programme was responsible for coining Lean. 
and visible leadership. The system was further detailed with defined standards, practices and tools belonging to each principle, but local adaption was emphasised in this structure allowing for context specific enablers and barriers in the production network. The latter prerequisite was due to the foreseen scaling effect.

The centralised team experience with Lean and production systems was based on one plant, one managing director and a relatively short response time from action to results. Now, the team had to deal with many plants, many management groups, different cultures, technologies and many views on how things should be done. From this scenario, it was obvious to the team that local change agents were needed to implement the system within given periods. To define and find these plant internal change agents, several strategies were outlined.

Traditionally the case company had strong unions, so having this formal and important group involved, engaged and represented in the implementation of the new productions system was part of the plan. Promises were given that the new system would provide a flatter hierarchical management structure, more autonomous and knowledgeable workers, and increased involvement in improvement work and decision making. Integrated in this plan was removal of the typical shift-leader or middle manager at shop floor level, supporting the new team structure where all members had certain responsibilities and roles.

Among the local change agent team, consisting of 2-4 people depending upon the plant size, at every plant at least one represented the union. Other important roles in the local team were quality manager and / or HR manager, aligning the new production system to existing systems having redundant objectives with regards to improving the organisation. Other members of the local team may be former shift managers, technical supervisors or highly regarded persons with a high degree of informal power in the organisation. This recruitment strategy to form local change agent teams was strongly rooted in the belief in the cultural and human dimension in implementing a new structure.

Thus, the new production system was immediately visible to every individual and team at plant level, by affecting daily work mode, as well as formal and informal structures. Much time was spent to align the central and the local teams' understanding of underlying production principles, methods, practices and tools, where the two teams worked closely, at operational level, in the pilot phase of implementing the production system. Short and long term improvement goals for each plant were defined together with plant management, and followed-up by revisions at all levels from the central change agent team. The mandate set by the main sponsor, the head of metal production division, was to decrease cost by $\mathrm{X}$ monetary units per ton metal produced within the period of three years. A reflection from the central team was lesser pressure from customers to improve production in the upstream industry. In the automotive sector, customers were always challenging and reviewing the case company, helping the improvement team to go forward. This drive was not that obvious in the new setting, and it had to be developed and emphasised by the central and local team. As the number of plants were introduced to the programme, the role of the central team changed slightly, from being more collaborative with the local teams, to be more workshop based and audit based. Maybe this was a natural evolution, since the number of central team members did not increase during the scale-up of implementation.

\section{Stage three}

From 2006 to about 2013 the production system had been through a development, implementation and operating phase, achieving the first major economic objective. Many "low-hanging fruit" had been picked, accumulating to a relatively good position on the global cost curve for smelters. Having in-place standardised processes, a clean and structured workplace, operating routines for the internal material flow, and more distributed and autonomous 
teams, the organisation was looking for new challenges. The company had simply reached a point where the gradient of improvement was declining, known as a plateau on the theoretical S-curve.

Employees report upon further potentials for improvement, but characterise these improvements as out of the reach or responsibility of individuals and teams. Hence, the existing production system structure was not designed to take the next step. Examples of such potentials often involved technical issues, investments, functions and actors outside the department or plant etc, meaning that complexity of problem at hand was not a quick fix anymore.

The sponsor, division management, recognised the need to upgrade the production system, re-launching it as a business system at an annual production system conference. A transition from production system to business system indicated that more company functions needed to be involved, to make any significant steps forward. The central improvement team was given the task of developing content to the new business system, without being assigned considerably more resources. Based on trends in ratio of improvements and feedback from the organisation, it was clear that the technology domain had to be involved. This department consisted of researchers, technicians and industrialisation resources, working on long-term projects to solve complex problem statements, and verifying results to be implemented in new investments 5-10 years ahead.

Thus, the strategy was to find formal and / or informal key resources within the technology department, to be allied with the central team. It was soon discovered that the technology department used external consultants to extend the department's capacity and capability, with regard to many topics: for instance how the department should make an innovation strategy for their new and on-going projects. This strategy rested on portfolio thinking of projects, categorising them according to time, complexity, investment, and success rate etc., totally parallel to the new business system.

Several steps were outlined to bridge these two universes. First, a formalised network structure was established between the actors' central improvement team, technology department, plants and a small group responsible for operational excellence across the plant structure. The idea behind this network was to establish practices for sharing information and knowledge between the actors, and to translate and diffuse relevant knowledge to the operational units. The links for this diffusion was technicians, belonging to the central technology department, appointed to be responsible to connect to and support local improvement teams at plant level. This role was to be a liaison, supporting the plants concerning technology issues, and to transmit feedback from plants and to the technology office. The ambition was to accelerate the improvement work locally by the best available knowledge, and to bridge the short and long-term focus respectively, from an operational and R\&D perspective.

Second, the central improvement team established a research projects called "step change" in mature organisations. The goal was to develop new knowledge on how large and multinational organisations can develop and sustain their improvement effort; a project also used internally to bridge the domains of operations and technology. Here, external researchers were ingrained in the boundaries and networks of the organisation, surfacing empirical findings to be discussed and refined in development of the network described above.

Third, in the wake of the trend Industry 4.0, the case company initiated attempts to map their potentials for automation and connectivity between man-machine. This initiative was clearly part of the step change, and business system, strategy to accelerate the company's improvement efforts. Again, externals were consulted to educate, inspire and map potentials, but responsibility was clearly linked to the business system. 
Realising the need for renewing of the production system towards a business system clearly points to technology as the missing link. Involving technology as an element to the business system adds complexity in terms of number of organisational interfaces to co-ordinate technology readiness in short and long term time horizon, risk and rewards and responsibilities. We see that the central improvement team remained the same, in terms of number and people, but their internal and external network for enabling further success grew considerably.

Working with the co-operation inside different companies and organisation, in collaboration with the centralised, team it became clear that evolution of the phases and performance system was driven by other mechanisms, not provided by the different theoretical systems. For instance, Lean contains lots of tools for implementation: ways of looking for waste, dealing with waste or non-value adding operations. However, looking at the corporation and the evolution in time it seems that implementation and maintains of the various systems relied upon very different organisational and social mechanisms. Overall, two different mechanisms were identified, mentor-sponsor and insider-outsider mechanisms.

The mentor-sponsor mechanisms are a specialised arrangement where the corporation recruits managerial talent and places them in different companies. Giving them room and challenges in order to develop their talents. Part of this was the movement between executive jobs in various companies in the corporation. Spending some years in one of the subsidiaries in Australia, then moving to the main office in Norway, before appointed CEO in a Brazilian company, can illustrate this development programme of executives. "Climbing the executive ladder," meant also binge part of the centralised team for the performance system when they were between executive jobs. Visiting subsidiaries and advancing how to work with the performance system was a vital part of the work in the centralised team.

The insider-outsider mechanism was a slightly different instrument. The central team or the mentor-sponsor mechanism recruited informal leaders, with good reputation internally in the actual company. In Norway with its long and strong labour union tradition, former union representatives were preferred in the positions of bringing the performance systems in use. In countries with other traditions, the recruitment of insider-outsiders were different, but still informal leaders of some sort was preferred. This recruitment process gave the insider-outsiders mandate and informal positions to initiate change.

In the beginning, with the customer driven improvement system, the people now occupying the central team were the insider-outsiders. As soon as they established the central team, during phase two, the two different mechanisms started to take shape. Having informal leaders as the main drivers of the change process made the initiation and maintains of the change processes much easier. Questions from the operators were answered quickly, and operators felt strong ownership to the process. One of them led it, was the general feeling.

Since the two mechanisms were operational during phase two, the number of people, insider-outsiders and mentor-sponsors, has not increased. Even during phase three, when the performance system developed with new issues and contents. It is a proof of true change where changes are embedded in daily operations.

\section{Conclusion}

This article illustrates how true change occurs in a multinational company. A Key point is that there are two mechanisms, mentor-sponsor and insider-outsiders. How these mechanisms work together and support each other is important. It enforces the feeling of ownership at many levels in the organisation and subsidiaries. Beside this, it also renews itself by constantly introducing new issues and content to the performance system. Another key 
point is that the mechanisms are not part of the content added to the performance system. When the performance system refocused from TQM to Lean, the mechanisms remained the same. This article argued that popular managerial and performance tools are not central, but rather how mechanisms for initiating and maintaining focus on performance.

\section{Acknowledgement}

This material is based on four research projects supported by the case company and the Norwegian Research Council over an 18 year period. Any opinions, findings, and conclusions are the authors'. In addition, we would like to thank the case company for their collaboration throughout the years, the Norwegian Research Council and numerous researchers that have been collaborating with us in these projects.

\section{References}

Abrahamson E., \& Eisenman M. (2008). "Employee-management techniques: Transistent fads or trending fashions?” Administrative Science Quarterly, 53(4), 719-744.

Anand G., Ward P. T., Tatikonda M. V., \& Schilling D. A. (2009). "Dynamic capabilities through continuous improvement infrastructure." Journal of Operations Management, 27(6), 444-461.

Barnes D. (2008). Operations Management - an International Perspective. London: Thomson Learning.

Bateman N. (2005). "Sustainability: the elusive element of process improvement." International Journal of Operations \& Production Management, 25(3/4), 261-276.

Bhasin S., \& Burcher P. (2006). "Lean viewed as a philosophy.” Journal of Manufacturing Technology Management, 17(1), 56 - 72.

Bralla J. G. (1999). Design for manufacturability handbook (2nd ed. ed.). New York: McGraw-Hill.

Bruner, E. M., \& Plattner, S. (1984). Text, play, and story: the construction and reconstruction of self and society : 1983 proceedings of the American Ethnological Society. Prospect Heights, Ill.: Waweland Press.

Chakravorty S. S. (2009). "Six Sigma programs: An implementation model." International Journal of Production Economics, 119(1), 1-16.

Christensen C. M. (1997). The innovator's dilemma: when new technologies cause great firms to fail. Boston, Mass.: Harvard Business School Press.

Clarke C. (2005). Automotive Production Systems and Standardisation. Heidelberg: Physica Verlag.

Cowen R. (2000). Exploiting the Earth. Baltimore: John Hopkins University Press.

Denzin, N. K. (1970). The research act in sociology: a theoretical introduction to sociological methods. London: Butterworths.

Denzin, N. K. (1978). The Research Act: A Theoretical Introduction to Sociological Methods. New York: McGraw-Hill.

Denzin, N. K., \& Lincoln, Y. S. (1994). Handbook of qualitative research. Thousand Oaks, Calif.: Sage.

Denzin, N. K. (2009). The Research Act: A Theoretical Introduction to Sociological Methods. New Brunswick: Aldine Trancaction. 
de Treville S., \& Antonakis J. (2006). "Could lean production job design be intrinsically motivating? Contextual, configurational, and levels-of-analysis issues.” Journal of Operations Management, 24(2), 99-123. doi:http://dx.doi.org/10.1016/j.jom.2005.04.001

El-Haik B., \& Al-Aomar R. (2006). Simulation-Based Lean Six-Sigma and Design for Six-Sigma. New Jersey: Wiley.

Ferdows K. (2008). "Managing the Evolving Production Network”. In Galavan R, Murray J., \& Markides C. (Eds.), Strategy, Innovation, and Change: Challenges for Management (pp. 149-163). Oxford: Oxford University Press.

Flick, U. (1998). An Introduction to Qualitative Research: Theory, Method and Applications. London: Sage Publications.

French W. L., \& Bell C. H. (1995). Organization development: behavioral science interventions for organization improvement. Englewood Cliffs, N.J.: Prentice-Hall.

Goel S., \& Chen V. (2008)." Integrating the global enterprise using Six Sigma: Business process reengineering at General Electric Wind Energy.” International Journal of Production Economics, 113(2), 914-927.

Guba, E. G., \& Lincoln, Y. S. (1989). Fourth generation evaluation. Newbury Park, Calif.: Sage.

Guion, L. A., Diehl, D. C., \& McDonald, D. (2011). Triangulation: Establishing the Validity of Qualitative Studies. University of Florida. Retrieved from http://edis.ifas.ufl.edu/fy394

Hackman J. R., \& Oldham, G. R. (1976). "Motivation through the Design of Work: Test of a Theory". Organizational Behavior and Human Performance, 16, 250-279.

Hasenkamp T. (2009). Designing for Robustness. (PhD thesis), Chalmers University of Technology, Gothenburg, Sweden.

Henderson R., Alamo J. D., Becker T., Lawton J., Moran P., \& Shapiro S. (1998). “The perils of excellence: Barriers to effective process improvement in product-driven firms." Production and Operations Management, $7(1), 2$.

Holberg C. (2006). "Maximum Complexity.” In Göranzon B., Hammarén M., Ennals R. (Ed.), Dialogue, Skill and Tacit Knowledge. Chichester: John Wiley \& Sons.

Holtskog H., Kaloudis A., Carayannis E., \& Ringen, G. (2018). Learning Factories: The Nordic Model of Manufacturing. New York: Palgrave Macmillan.

Holweg, M. (2007). “The genealogy of lean production”. Journal of Operations Management, 25(2), 420-437.

Hounshell D. A. (1984). From the American System to Mass Production, 1800-1932: The Development of Manufacturing Technology in the United States. Baltimore: Johns Hopkins University Press.

Hubka V., \& Eder W. E. (1988). Theory of Technical Systems: A Total Conept Theory for Engineering Design. Heidelberg: Springer-Verlag.

IfM. (2007). Making the right things in the right places: A structured approach to developing and exploiting 'manufacturing footprint' strategy. Retrieved from Cambridge, UK:

Ishikawa K. (1985). What is total quality control?: the Japanese way. Englewood Cliffs, N.J.: Prentice-Hall. 
Kamata E. S. (2002). Influence of Psychological Factors on Product Development, Lessons from Aerospace and Other Industries. Dordrecht: Kluwer Academic Publishers.

Klein J. A. (2004). True change: how outsiders on the inside get things done in organizations. San Francisco: Jossey-Bass.

Krafcik J. F. (1988). “Triumph of the lean production system”. MIT Sloan Management Review, 30(1), 41-52.

Levin M. (2004). “Organising Change Process; Cornerstones, Methods, and Strategies.” In J. J. Boonstra (Ed.), Dynamics of Organisational Change and Learning (pp. 71-84). Chichester, England: John Wiley \& Sons Ltd.

Lewin, K. (1951). Field Theory in Social Science: Selected Theoretical Papers. London: Travistock.

Liker J., \& Morgan J. (2006). “The Toyota Way in Services: The Case of Lean Product Development.” The Academy of Management Perspectives, 20(2), 5-5-20.

Liker J. K. (2004). The Toyota Way: 14 Management Principles from the World's Greatest Manufacturer. New York: McGraw-Hill.

Liker J. K., \& Hoseus M. (2008). Toyota Culture, The Heart and Soul of the Toyota Way. New York: McGrawHill.

Liker J. K., \& Meier D. (2006). The Toyota Way Fieldbook; A Practical Guide for Implementing Toyota's 4P's. New York: McGraw-Hill.

MacDuffie J. P. (1995). "Human Resource Bundles and Manufacturing Performance: Organizational Logic and Flexible Production Systems in the World Auto Industry." Industrial and Labor Relations Review, 48(2), 197221.

March J., Simon H., Hickson D. (1994). Organizations. Vol. 15, pp. 786-787.

March J. G. (1988). “The technology of foolishness.” In March J.G. (Ed.), Decisions and Organizations (pp. 253265). Blackwell: Oxford.

Maritan C. A., Brush T. H., \& Karnani,A. G. (2004). "Plant roles and decision autonomy in multinational plant networks." Journal of Operations Management, 22(5), 489-503.

Miles, H., \& Huberman, M. (1994). Qualitative Data Analysis: A Sourcebook. Beverly Hills, CA: Sage Publications.

Monden Y. (1983). Toyota Production System: Practical Approach to Production Management. Norcross: Industrial Engineering and Management Press.

Netland T. H., \& Aspelund A. (2012).” Company-specific Production Systems and Competitive Advantage: A resource-based view on the Volvo Production System". International Journal of Operations \& Production Management, FORTHCOMING.

Netland T. H., \& Sanchez E. (2014). "Effects of a Production Improvement Programme on Global Quality Performance: The Case of the Volvo Production System.” The TQM Journal, 26(2), 1754-2731.

Nomura M., \& Jürgens U. (1995). Binnenstrukturen des japanischen Produktivïtätserfolges: Arbeitsbeziehungen und Leistungsregulierung in zwei japanischen Automobilunternehmen. Berlin: Sigma.

Oakland J. S. (2003). Total quality management: text with cases. Amsterdam: Butterworth-Heinemann. 
Ohno T. (1988). Toyota Production System: Beyond Large-Scale Production. New York: Productivity Press.

Patton, M. Q. (2002). Qualitative research \& evaluation methods.

Robertson R. (1995). “Glocalisation: Time-Space and Homogeneity-Heterogeneity.” In M. F. e. al (Ed.), Global Modernities. London: Sage.

Shah R., \& Ward,P. T. (2003). Lean manufacturing: context, practice bundles, and performance. Journal of Operations Management, 21(2), 129-149.

Shah R., \& Ward P. T. (2007). Defining and developing measures of lean production. Journal of Operations Management, 25(4), 785-805.

Smith, M., \& Kleine, P. (1986). Qualitative Research and Evaluation: Triangulation and Multimthods Reconsidered. In D. Williams (Ed.), Naturalistic Evaluation (New Directions for Program Evaluation). San Francisco: Jossey-Bass.

Spear S., \& Bowen H. K. (1999). "Decoding the DNA of the Toyota Production System.” Harvard Business Review, 77(9/10), 97-106.

Taylor F. W. (1911). The Principles of Scientific Management New York: Harper Bros.

Trikman P. (2010). “The critical success factors of business process management." International Journal of Information Management, 30(2), 125-134. doi:10.1016/j.ijinfomgt.2009.07.003

Westie, F. R. (1965). The American Dilemma: An Empirical Test. American Sociological Review, 30(4), $527-$ 538. doi: $10.2307 / 2091342$

Whitley R. (2007). Business Systems and Organizational Capabilities, the Institutional Structuring of Competitive Competences. Oxford: Oxford University Press.

Womack J. P., Jones D. T., \& Roos D. (1990). The machine that changed the world. New York: Simon \& Schuster.

Yeasmin, S., \& Rahman, K. F. (2012). 'Triangulation' Research Method as the Tool of Social Science Research. BUP Journal, 1(1), 154 - 163.

\section{About the authors}

Geir Ringen is Professor at NTNU (Norwegian University of Science and Technology, department of Mechanical and Industrial Engineering). Research interests lie in the field of studying socio-technical concerns, ranging from organisational to more technology based studies. His latest book is Learning Factories - the Nordic Model of Manufacturing (Palgrave 2018).

Halvor Holtskog is professor at NTNU (Norwegian University of Science and Technology, department of Industrial Economic and Technology). He has published the books and articles socio-technical concerns, ranging from organizational towards technology based studies. His two latest books are Learning Factories - the Nordic Model of Manufacturing (Palgrave 2018) and Coping with the future - rethinking assumptions for society, business and work (Routledge 2018). 